\title{
Effect of crude aqueous leaf extract of Viscum album (mistletoe) in hypertensive rats
}

\author{
O.E. Ofem, A.E. Eno, J. Imoru, E. Nkanu, F. Unoh, J.O. Ibu
}

Department of Physiology, College of Basic Medical Sciences,

University of Calabar, Calabar, Nigeria

Received: 29.4 .2005

Revised: 3.7.2006

Accepted: 3.8 .2006

Correspondence to:

A. E. Eno

E-mail: nkineno2000@yahoo.co.uk

\section{Introduction}

Hypertension is one of the leading causes of disability, morbidity and mortality among the populace; it is the most common chronic illness the world faces. ${ }^{[1,2]}$ Viscum album (mistletoe) is an evergreen partial parasite that grows on branches of deciduous plants like oak, chestnut, black poplar, elms, pines, apples, citrus, etc. ${ }^{[3]}$ It is widely distributed throughout Europe, North Africa, Austria and in Nigeria. ${ }^{[4]}$ Mistletoe is known by different names, e.g., European mistletoe, Birdlime, all heal, mystyldene, devil's fuge, Phoradendron serotinum, Golden Bough, Muerdago, visco, Gu”mil'ioc” (meaning 'all-heal'), 'Golden Bough', etc. ${ }^{[5]}$ Its berry produces a sticky substance hence the alternative name 'birdlime'. Phytochemical screening of Tapinanthus dodoneifolius (DC) Danser called 'Kauchi' in Hausa a species of African mistletoe showed the presence of anthraquinones, saponins and tannins. ${ }^{[6]}$ The primary chemical constituents of European mistletoe has been found to vary according to the host plant, but typically include glycoprotein, polypeptides (viscotoxin), flavonoids, flavonol agylcones (methyl ethers of quercetin and kaempforal), lectins such as $V$. album agglutinin I, II and III, triterpenes, saponins, caffeic acid, lignans, choline derivatives related to acetylcholine, vitamin C, histamine, resins, thionins cardionolids and phenolic compounds. ${ }^{|7-9|} \mathrm{A}$ decoction of the leaves of mistletoe is traditionally used in the treatment of hypertension and to alleviate symptoms of hypertension such as headache, dizziness, palpitation, etc. ${ }^{[10,11]}$ There exists little scientific literature on the effect of $V$. album on blood pressure (BP). The present study therefore, is aimed at investigating the scientific basis to the claims of the traditional herbalists on the usefulness of $V$. album leaves extract to lower BP. 


\section{Materials and Methods}

\section{Preparation of the crude extract}

About a kilogram of fresh leaves of $V$. album from the host plant (citrus) were collected from a local plantation in Akpabuyo Local Government Area, Calabar-Nigeria, during the raining season. The leaves were first washed free of sand and debris. Wash water was blotted off and the leaves ground to paste. A quantity of the paste $(50 \mathrm{~g})$ was weighed and Soxhlet extracted with $150 \mathrm{~mL}$ distilled water at $100^{\circ} \mathrm{C}$ for 8-10 hour. Where larger ground samples were used, extraction was done under reflux with an appropriate volume of distilled water. The extract was slowly evaporated to dryness in vacuo at $40^{\circ} \mathrm{C}$ using a rotary evaporator. A total yield of $31 \%$ was obtained. Weighed samples of the extract were then used to prepare the stock solution.

\section{Acute toxicity test}

About 70 male albino Wistar mice (18-20 g) were randomly assigned to seven cages of 10 animals per cage. They were allowed a week for adaptation. Each group then received one of the following doses: $0,125,250,500,1000,2000$ and $4000 \mathrm{mg} / \mathrm{kg}$ body weight of the extract, i.p. The maximum volume injected was $0.2 \mathrm{~mL}$. The mice were allowed free access to food and drinking water. The mortality in each cage was assessed 24 hours after the administration of the extract. Percentage mortality was converted to probit and plotted against the $\log _{10}$ dose of the extract from which the $\mathrm{LD}_{50}$ was extrapolated. ${ }^{[12]}$

\section{Measurement of BP and heart rate (HR)}

About 42 male albino Wistar rats (initially weighing between 130 and $150 \mathrm{~g}$ ) were randomly assigned into three batches, the normotensive (NMT), renal artery-occluded hypertensives $(\mathrm{ROH})$ and the salt-induced hypertensives (SIH). The normotensives (18 rats) were further divided into three groups of six rats each. These were the control, the sham-operated and the extract-treated normotensives. Each of the SIH and ROH groups (12 rats) was further divided into two subgroups $(n=6)$ as extract treated and untreated. Treatment with the extract $\left(150 \mathrm{mg} / \mathrm{kg}\right.$, dose selection was based on the $\left.\mathrm{LD}_{50}\right)$ was done orally, once daily using an orogastric tube. Renal occlusion was carried out by occlusion of left side artery with a ligature shaped into a figure of eight. ${ }^{[13]}$ Operated rats received 100000 i.u. procaine penicillin (i.m.) to prevent post-operative infection. The normotensive rats had free access to food and drinking water, while the $\mathrm{ROH}$ group had free access to food but restricted water intake (1\% saline) for six weeks. The SIH group was placed on a high salt diet $(8 \% \mathrm{NaCl})$ and $1 \%$ saline drinking water for 6 weeks. ${ }^{.14]}$ Only animals with mean arterial pressure (MAP) between 120 and $130 \mathrm{mmHg}$ were considered hypertensive. At the end of the feeding period (6 weeks), each rat was anaesthetized with $6 \%$ pentobarbitone $(0.1 \mathrm{~mL} / 100 \mathrm{~g}$ body weight i.p.). The trachea was intubated, the femoral vein and carotid artery were cannulated (Portex cannulae, external diameter $1.02 \mathrm{~mm}$, internal diameter $0.75 \mathrm{~mm}$ ), for drug administration and blood pressure measurements, respectively. The blood pressure transducer (M/N MB5049/41 - 6A) was connected to 4D-polygraph (Grass Instrument Division, USA) (M/N 30-V7404-00) to record the BP and HR.
In the second group of normotensive rats, graded doses of the extract $(2.5-20 \mathrm{mg} / \mathrm{kg})$ were administered intravenously in a cumulatively manner. The administration of the extract was always preceded by flushing $0.5 \mathrm{~mL}$ saline intravenously. Propranolol $(0.5 \mu \mathrm{g} / \mathrm{kg})$, noradrenaline $(1.0 \mu \mathrm{g} / \mathrm{kg})$ and atropine $(1.5 \mu \mathrm{g} / \mathrm{kg})$ were administered i.v. to study the interaction and the probable mechanism(s) of action of the extract. The MAP was calculated from the relationship:

$$
\mathrm{MAP}=\mathrm{DP}+(\mathrm{SP}-\mathrm{DP}) \frac{1}{3}
$$

where DP and SP are systolic and diastolic pressures, respectively.

\section{Statistical analysis}

Data are presented as mean \pm SEM. Correlation/ Regression analysis was employed as a statistical tool for some data. Others were compared using one-way analysis of variance (ANova) followed by à post-hoc least square difference (LSD) using SPSS 7.5 for windows. A $P$-value less than 0.05 was considered statistieally significant.

\section{Results}

\section{Acute toxicity test}

The $\mathrm{LD}_{50}$ value for the crude extract from $\mathrm{V}$. album leaves was $420.70 \mathrm{mg} / \mathrm{kg}$ mice i.p. The higher dose recipients (2000$4000 \mathrm{mg} / \mathrm{kg}$.i.p.) showed depressed respiration with occasional gasps about 6-8 hours post-injection. Death followed after few minutes exhibition of tremor of the fore limbs and hind limbs Rectal temperature taken between 2 and 4 sec. after death was about $32 \pm 3.5^{\circ} \mathrm{C}$ [Figure $1 \mathrm{~A}$ ].

\section{Dose-effect relationship}

The crude extract of $V$. album leaves $(2.5-20 \mathrm{mg} / \mathrm{kg}$. i.v.) produced a dose-dependent lowering of arterial BP in the normal rat [Figure 1B]. A straight line regression was fitted for the linear portion of the curve, from which the $\mathrm{ED}_{50}$ was determined. The $\mathrm{ED}_{50}$, was $20.15 \pm 2.7 \mathrm{mg} / \mathrm{kg}$. An important observation was, the extract had quick onset action, with

Figure 1A: Effect of the crude mistletoe leaf extract on the mortality of mice (values \pm SEM), $n=10$ per group

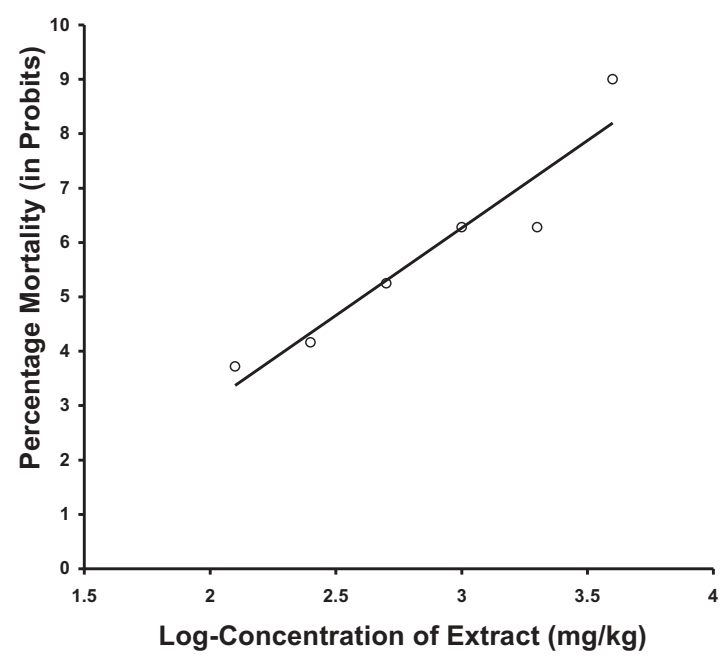


Figure 1B: Blood pressure changes following the administration of graded doses of the crude mistletoe leaf extract to normotensive Wistar rats (are mean \pm SEM)

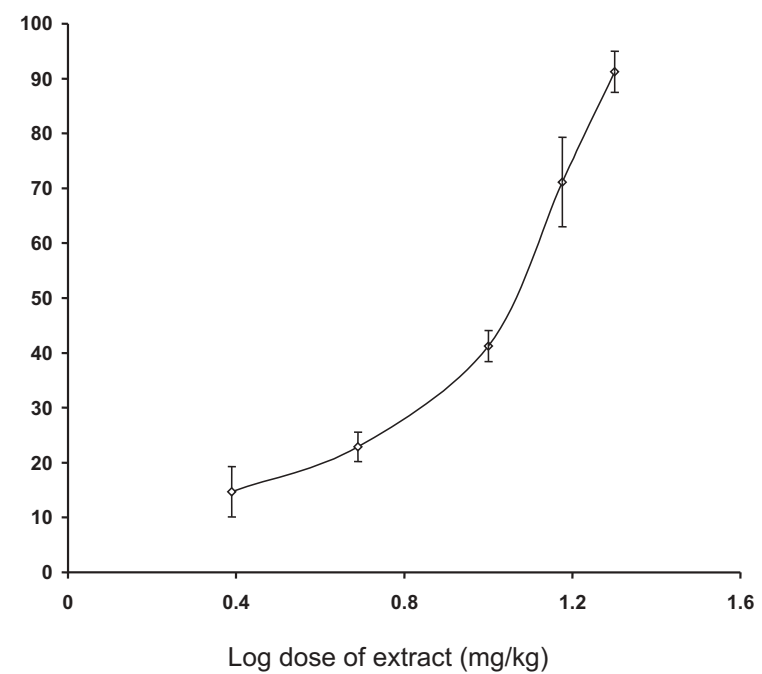

latency of 2-4 sec, depending on the concentration. $B P$ and $H R$

The MAP in the anesthetized normotensive control rats was $97.50 \pm 3.28 \mathrm{mmHg}$; the crude extract $(150 \mathrm{mg} / \mathrm{kg}$ i.v. $)$ significantly reduced blood pressure of normotensive controls [Figure 2]. The salt-induced hypertensive rats had a MAP of $130.00 \pm 2.58 \mathrm{mmHg}$, of $33.33 \%$, higher than the control. Similarly, animals with unilateral occlusion of the renal artery a MAP of $135.50 \pm 5.75 \mathrm{mmHg}$ that was higher $(105.00 \pm 7.18 \mathrm{mmHg})$ as compared to sham-

Figure 2: Crude extract on the $\mathrm{BP}(\mathrm{mmHg})$ of various groups of Wistar rats (values \pm SEM)

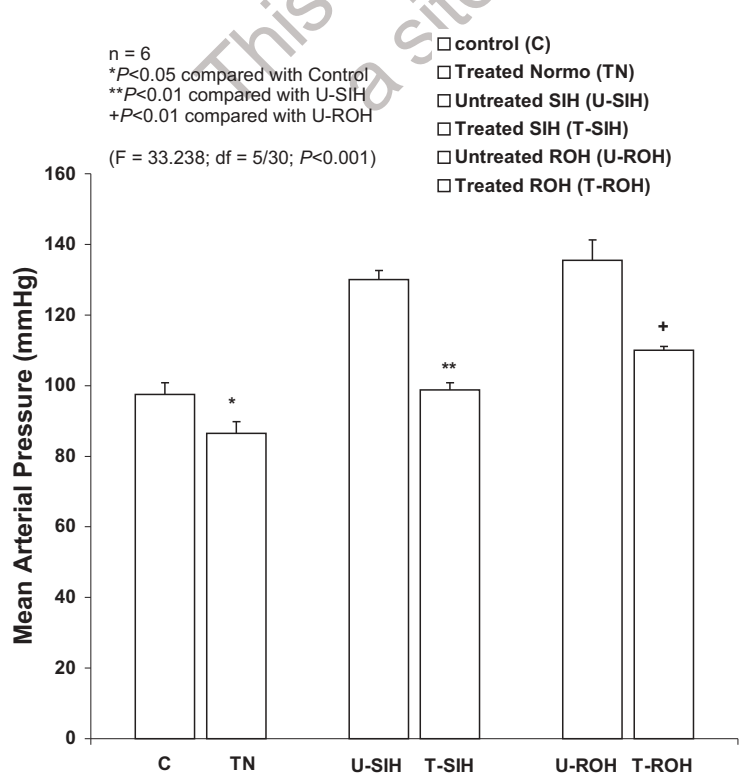

Figure 3: Histogram showing the effect of administering the crude extract (150 mg/kg. oral) on the Heart rates (beats $/ \mathrm{min}$.) of various groups of Wistar rats, measured simultaneously with the BP. Given are the mean values \pm SEM, $n=8$

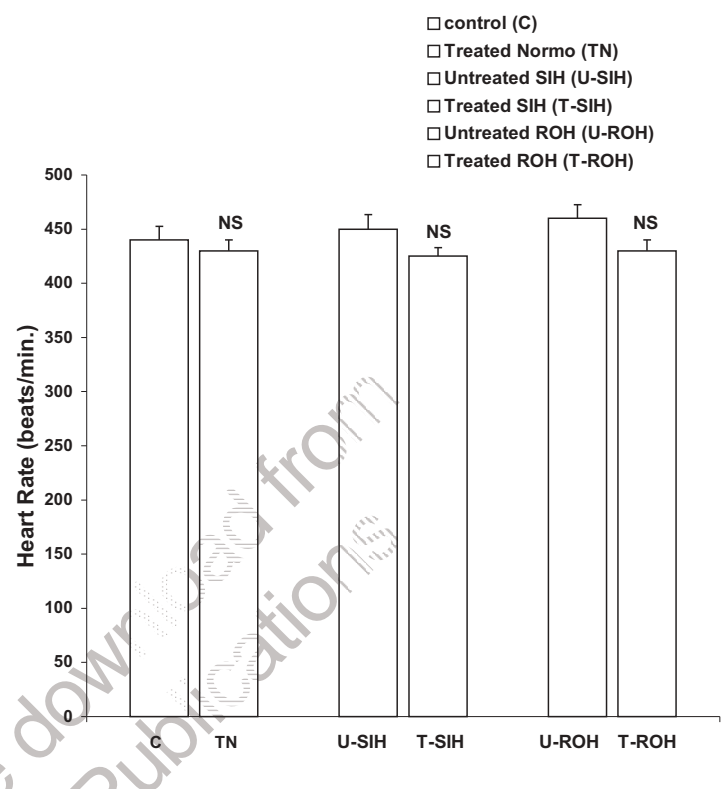

Figure 4: (a) Typical mechanical recordings showing the blocking action of propranolol (Prop. $0.5 \mu \mathrm{g} / \mathrm{kg}$. i.v) on the action of the extract (15 mg/kg. i.v) (b) the failure to block extract-induced reduction of BP by atropine sulphate $(1.5 \mu \mathrm{g} / \mathrm{kg}$. i.v), (c) and the blocking of NAinduced increase in BP by the extract
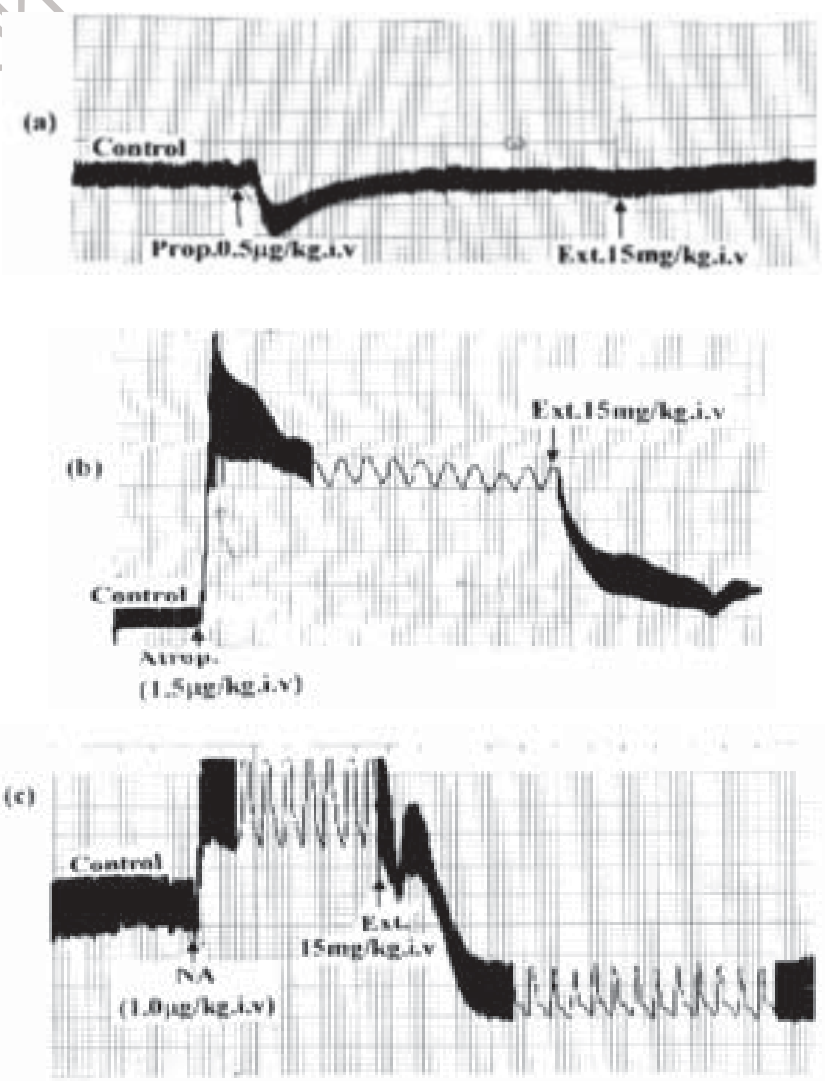
operated controls. However, the extract treated $(150 \mathrm{mg} /$ $\mathrm{kg}$ p.o.) SIH and ROH hypertensive animals had significantly lower MAP $(P<0.01)$ as compared to their respective untreated groups. These reductions were about 23.98 and $18.82 \%$ for the SIH and ROH subgroups, respectively (\% untreated groups) [Figure 2].

There was no difference in the heart rate between the normotensive controls and sham-operated rats. The extract did not influence the HR significantly (\% control) in any of the groups [Figure 3].

Propranolol $(0.5 \mu \mathrm{g} / \mathrm{kg}$ i.v. $)$ blocked the action of the extract (15 mg/kg i.v) on BP [Figure 4A]. However, atropine $(1.5 \mu \mathrm{g} /$ $\mathrm{kg}$ i.v.) did not prevent the extract-induced decrease in BP [Figure 4B]. Noradrenaline $(1.0 \mu \mathrm{g} / \mathrm{kg}$ i.v. $)$ produced an increase in BP of normotensives [Figure 4C]. This increase was blocked by the administration of the extract.

\section{Discussion}

In this study, we measured the arterial BP and the heart rate of both the normotensive and hypertensive (using saltloading and renal-occlusion methods) rats, with a view to analyze the scientific basis for the use of $V$. album (mistletoe). Salt loading produces hypertension through vasopressor effect of accumulated catecholamines in circulation. ${ }^{[15-17]}$ On the other hand, the mechanism for hypertension development in renal artery occlusion model is via the renin-angiotensin system. ${ }^{[18]}$ Both the methods therefore, produce powerful vasopressor activity. However, the salt-loading method could also produce some excitatory action on the heart. ${ }^{[16,19]}$ Thus, hypertension induced by salt-loading or renal artery occlusion in animals including man ${ }^{[16]}$ cannot be relieved by agents which do not have action on the peripheral blood vessels.

In the present study, the crude mistletoe extract significantly lowered the BP but had noeffect on the heart rate in normotensive rats. This may not be surprising since antihypertensives like captopril (an angiotensin converting enzyme inhibitor) do not affect the heart rate of renovascular hypertensives but lower the BP. ${ }^{\lfloor 91}$ The hypotensive activity of captopril is also contributed by the depression of baroreceptor sensitivity which reduces the activity on the vasomotor centre (VMC), causing a reduction in vasopressor effect. ${ }^{[18]}$ It is possible that the reduction in $\mathrm{BP}$ by the mistletoe extract without any alteration in HR may be due to the vasopressive effect. That is, the depressor effect of the extract is probably due to the action of the extract on alpha- 1 adrenoceptors, resulting in reduction of peripheral cardiovascular (specifically the blood vessels) drive. Alternatively, the extract may contain agonist-like agents that act on the beta-2 adrenoceptors to produce a relaxant action on the vascular smooth muscles, since propranolol a beta-blocker was able to block the action of the extract. The lack of influence of the extract on the heart rate in normotensive as well as hypertensive rats suggests that it could be predominantly acting on the peripheral blood vessels.

Salt induced hypertension is due to the release of adrenomedullary catecholamines. ${ }^{[14,15,17]}$ Therefore, the marked depression of blood pressure by the extract in SIH group tends to suggest that a reduced amount of catecholamine release is also possible. The BP reduction by the extract is less likely via the cholinergic muscarinic mechanism since atropine failed to block.

In renovascular hypertension, it is reported to trigger the release of renin from the kidneys that activates the reninangiotensin system to produce a potent vasoconstrictor (angiotensin II) causing vasopressor effect. ${ }^{[19]}$ It has also been shown that there is an increase in catecholamine synthesis (increased tyrosine hydroxylase activity) in the adrenal glands of renovascular hypertensive rats. ${ }^{[14,20]}$ It therefore appears that the marked depression of $\mathrm{BP}$ in SIH and $\mathrm{ROH}$ rats may have resulted from a depressed release of adrenomedullary catecholamines in response to the administration of mistletoe crude extract. This possibility is considered because a persistent, markedly elevated plasma adrenal level was observed $\mathrm{SIH}^{[15,17]}$ and $\mathrm{ROH}^{[14]}$ rats. This is likely to cause a consequent depression (negative feedback) in the quantity of released adrenomedullary catecholamines in established saltinduced and renovascular hypertension. ${ }^{20]}$ Thus, the release of adrenaline from the adrenal medulla would remain depressed as a consequence of enhanced feedback control and/or inhibition of the mechanism by the extract. The inhibition of the noradrenaline-induced increase in BP by the mistletoe extract further supports the implication of the sympathetic nervous system.

\section{Conclusion}

The crude extract from the leaves of $V$. album (mistletoe) probably contains several pharmacologically active constituents. In normotensives animals, one such group may be catecholamine-like blocking agent(s), showing predominantly alpha-1 adrenoceptor antagonist action or agonist-like agents which may be stimulating the beta- 2 adrenoceptors to produce the depressor effect. Further studies are needed to identify the active principle(s) responsible for the antihypertensive activity of the extract followed by specific experiments to ascertain the receptor subtype involved.

\section{Acknowledgement}

The authors gratefully acknowledge the technical assistance of Mr. Udo, E. Ekong of the Physiology Department, University of Calabar, Nigeria. We also wish to thank Miss Idorenyin, D. Udo and Miss Bassey, B. for typing the manuscript.

\section{References}

1. Akinkigbe 0 . Current epidermiology of hypertension in Nigeria. In: the achieves of Ibadan Medicine. Int J Med Sci 2001:1:1.

2. Schutte A, Van Rooyen J, Huisman H, Kruger H, Malan N, De J. Dietary risk markers that contribute to the etiology of hypertension in black South African children. The THUSA BANA study. J Hum Hypertens 2003:17:29-35.

3. Hutt N, Kopferschmit-Kubler M, Cabalium J, Purohit A, Alt M, Pauli G. Anaphylactic reactions after therapeutic injection of Mistletoe (Viscum album L). Allergol Imrnunopathol (Madr) 2001:29:201-3.

4. Frohne D, Pfander H. Mistletoe. In: A colour Atlas of Poisonous Plants. $1^{\text {st }}$ ed. Wolfe Pub: Londonl 1984. p. 155-6.

5. Swain L. Mistletoe. Gale encyclopedia of alternative medicine. 1995. p. 4.

6. Deeni Y, Sadiq N. Antimicrobial properties and phytochemiical constituents of the leaves of African mistletoe (Tapinanthus dodoneifolius (DC) Danser) an ethnomedicinal plant of Hausa land, North Nigeria. J Ethnopharmacol 2002:83:235-40.

7. Edlund U, Hensel A, Frose D, Pfuller U, Scheffler A. Polysaccharides from fresh Viscum album L. berry extract and their Interaction with Viscum album aggl. I. Arzneimi Helforschung 2000:50:645-51.

8. Wollenweber E, Wieland A, Haask A. Epicutical wax and flavonol aglycones 
of the European Mistletoe. Viscum album L. Z Naturforsch 2000:55:311-7.

9. Lyu S, Park S, Cheng B, Park W. Comparative study of Korean (Viscum album var. coloratum) and European mistletoe (Viscum album L.) Arch Pharmacol Res 2000:23:590-8.

10. Fernandez T, Wagner M, Varela B, Ricco R, Hajos S, Gurni A. Study of an Argentine Mistletoe, the hemiparasite. Ligaria cuneifolia (R.et. R). Tiegh (Loranthaceae). J Ethnopharmacol 1998:62:25-34.

11. Deliorman D, Calis T, Ergun F, Dogan B, Buharalioghu C, Kanzik K. Studies on the vascular effects of the fractions and phenolic compounds isolated from Viscum album. J Ethnopharmacol 2002:72:323-39.

12. Miller L, Tainter M. Estimation of EC50 and its error by means of log. Probit graph paper. Proc Soc Exp Biol Med 1944:57:261-9.

13. Ganguli M Lobian L Iwai J. Cardiac output and peripheral resistance in strain of rats sensitive to $\mathrm{NaCl}$ hypertension. Hypertension 1979:1:3-7.

14. Osunkwo U, Eferakeya, A. Plasma catecholamines levels during development of DOCA, renal and spontaneous hypertension in rats. Med Sci Res 1987:15:971-2.
15. Obiefuna $P$, Sofola $\mathrm{O}$, Ebeigbe $\mathrm{A}$. Contractile response of normotensive rat aorta to serum from salt-loaded Sprague Dawley rats. Nig J Physiol Sc 1992;8:54-7.

16. Nicholas M, Kiowski W, Zweifler A, Julius S, Schork M, Greenhouse J. Plasma norepinephrine variations with dietary sodium intake. Hypertension 1980;2:29-32.

17. Sofola O, Dina I, Egbe P, Owolabi O. Dietary salt loading enhance baroreceptor reflex sensitivity in Sprague-Dawley-rats. Nig J Physiol Sci 1991;7:95-9.

18. Goldblatt H. The renal origin of hypertension. Physiol Rev 1947;27: 120-65.

19. McGrath B. Matthews $P$, Johnson C. Acute changes in blood pressure and vasoactive hormones after captopril in hypertensive patients. Clin Exp Pharmacol Physiol 1980:7:487-91.

20. Osunkwo U, Eferakeya A. Attenuated hypothalamic secondary pressor responsiveness and the effect of gallopamil or hydrallazine in DOCA-salt and renal hypertensive rats. Nig J Physiol Sci 1994;1:1-5.

\section{Announcement}

IMARD: The age old structure for scientific papers

Attracting readers: The importance of title and abstract

Tables and Figures: Making figures worth 1000 words

The 'structured discussion': The evidence based discussion

Standardized reporting guidelines: The helping hands

Reporting statistics: The common errors editors won't miss to pickup

The peer review process: Easier to pass through when you know how it works

'I wish I had written that paper': The publishable paper

Authors vs. contributors: The importance of names in byline

Ethical conduct of research: When and how of IRBs

and more...

For details: www.jpgmonline.com/writecon.asp 